\title{
Does Belief in Dualism Protect against Maladaptive Psycho- Social Responses to Deep Brain Stimulation? An Empirical Exploration
}

\author{
Jason Shepard \& Joshua May \\ Published in the American Journal of Bioethics: Neuroscience 5(4): 40-42 (2014).
}

[Note: This is the penultimate draft. Final version is at www.tandfonline.com.]

\begin{abstract}
We provide empirical evidence that people who believe in dualism are more likely to be uncomfortable with Deep Brain Stimulation (DBS) and to view it as threatening to their identity, humanity, or self. It is (neurocentric) materialists - who think the mind just is the brain - that are less inclined to fear DBS or to see it as threatening. We suggest various possible reasons for this connection. The inspiration for this brief report is a target article that addresses this issue from a theoretical perspective.
\end{abstract}

Mecacci and Haselager (M\&H; this issue) offer several interesting hypotheses about the negative psycho-social side-effects of having an electronic device implanted in one's brain via Deep Brain Stimulation (DBS), such as feeling like a different person or a machine. The authors argue that one's beliefs about the relation between the mind and the body (e.g., dualism vs. materialism) can promote or attenuate such "psycho-social maladaptations." One of their core hypotheses is that a belief in dualism protects against these effects, since "the stimulations will not touch one's 'genuine self" if one believes "the brain is not involved in the very nature of your mind and self" (ms. p. 3). On the other hand, Mecacci and Haselager claim a belief in "neurocentric" materialism may lead one to "feel exposed to a personal disruption, for a stimulator interferes with what is responsible for the entire personal dimension, the brain" (ms. p. 3).

If $\mathrm{M} \& \mathrm{H}$ are right, people who accept dualism should (a) be less likely to view DBS as a threat to personal identity, (b) be more comfortable with DBS in general, and (c) not see DBS as a procedure that would make people "less human." These views, if true, are likely to hold for DBS patients as well as the general public. For example, nonDBS patients who are dualists should see DBS as less of a threat to personal identity than materialists would. 
While we believe M\&H's hypothesis is a plausible one, an opposing view also seems plausible. For example, dualists are more likely to believe that we have a special essence, or a soul, that makes us, us (Bloom, 2004), and they may view the brain as a place where the soul interacts with the body (Descartes, 1641/1996). This view may lead dualists to be particularly wary of DBS, fearing that DBS will interfere with the soul via its connection with the brain. Materialists, on the other hand, are less likely to believe that people have soul-based special essences, and thus materialists may be more comfortable with DBS, precisely because they are less inclined to believe there is an essence to be manipulated (cf., Nahmias, et al., forthcoming).

Of course, the competing predictions made by these hypotheses are an empirical matter, not merely a conceptual one. $\mathrm{M} \& \mathrm{H}$ appreciate this point as much as anyone. They specifically note the dearth of empirical research on this topic, and one of the goals of their paper is to "[make] a case for further empirical investigation" (ms. p.4). We do exactly that, reporting a study that we hope will serve as a starting point for a developing empirical debate.

\section{Method}

We recruited 82 people via Amazon Mechanical Turk to participate in the study. Participants were administered the Free Will Inventory (FWI; Nadelhoffer, et al., 2014), which includes a belief in Dualism subscale. They were then asked to read a short passage introducing the uses and effects of DBS, followed by a questionnaire regarding DBS and personal identity, which contained 16 questions. Participants responded to all questions using a 7-point Likert scale ranging from 1 strongly disagree to 7 strongly agree.

The 16 questions formed several reliable composites. Ten questions formed a Change in Personal Identity composite $(\alpha=.913)$ - e.g., "DBS fundamentally changes who a person is," and "I would worry that if I went through DBS, I would no longer recognize myself as the same person." Two of the questions formed a DBS Makes One Less Human composite $(\alpha=.857)$ — viz., "In a way, DBS makes one less human" and "In a way, DBS makes one more cyborg-like." Two other questions formed a Comfort with Undergoing DBS composite $(\alpha=.887)$ - e.g., "I would feel comfortable undergoing DBS if it was medically recommended." Finally, two questions formed a Mind is Brain composite $(\alpha=.768)$ - e.g. "The success of DBS provides strong evidence that the mind just is the brain and not some kind of special entity." We conducted correlational analyses between these four composites and the Dualism subscale of the FWI.

M\&H's view predicts a negative correlation between scores on the Dualism subscale and the Change in Personal Identity composite, since they claim dualism acts as a protective factor against changes to the "genuine self." Similarly, they should predict a negative correlation between the dualism subscale and the DBS Makes One Less Human composite, because they claim dualism allows people "to gain some distance from the unsettling idea of potentially becoming a human machine hybrid" (ms. p. 10). Lastly, they should predict a positive correlation between Dualism and Comfort with Undergoing DBS composite, because DBS should not be seen as threatening to the dualist for the reasons mentioned above. Since Mind is Brain 
composite is a measure of neurocentric materialism, we would expect the results from this composite to negatively correlate with the Dualism subscale of the FWI.

\section{Results}

Dualism strongly negatively correlated with the belief that the mind is brain, $r=-.612, p$ $<.001$, suggesting that people who believe less strongly in dualism believe more strongly in neurocentric materialism. Contrary to M\&H's hypothesis, belief in dualism was not correlated with belief in DBS changing personal identity, $r=-.034, p=.764$. Moreover, belief in dualism positively correlated with the belief that DBS makes one less human, $r=.288, p=.009$. In other words, the more one believed in dualism, the more one tended to believe that DBS made one less human. Opposite the prediction of $\mathrm{M} \& \mathrm{H}$, belief in dualism was negatively correlated with feeling comfortable undergoing DBS, $r$ $=-.270, p=.014$. The Mind is Brain composite-our proxy measure of neurocentric materialism-positively correlated with feeling comfortable with undergoing DBS, $r=$ $.315, p=.004$. In other words, dualists tend to be less comfortable with the prospect of undergoing DBS, while neurocentric materialists tend to be more comfortable.

\section{Discussion}

This set of results taken together poses a challenge to M\&H's hypothesis, and we believe provide initial evidence in favor of the opposing view. That is, our data support the view that dualist are more likely to believe that people have special essences that interact with and can be interfered with via the brain, and because of this, dualist, not materialists, find DBS more threatening.

Even if we are right, this isn't to say that $\mathrm{M} \& \mathrm{H}$ were not on the right track. One of their hypothesis was that the "frequently reported maladaptations might be partially caused by a conceptual shift away from dualism and towards a 'neurocentric' materialism, promoted by the scientific explanation [by medical experts]" (abstract). Of course, the reasoning behind this "shift hypothesis" (as we might call it) is their claim that dualism acts as a protective factor, and that the shift away from dualism erodes that protection $^{1}$.

While our data challenge their reasoning behind the shift hypothesis, another version of the shift hypothesis may still explain some of the psycho-social maladaptations associated with DBS. A belief in special essences, in a soul, is a deeply held belief by many (Bering, 2006), and DBS may challenge this deeply held belief. The challenging of a deeply held belief can be unsettling and leads to psycho-social maladaptations. Under this view, and contra $\mathrm{M} \& \mathrm{H}$, it is not the content of the belief that matters (e.g., dualism vs. neurocentric materialism), but rather it is the fact that a deeply held belief is being challenged in a way that leads to inconsistences and conflict within

\footnotetext{
1 It's not clear to us whether M\&H saw their "shift hypothesis" as a separate hypothesis from the "dualism as protective" hypothesis. However, by separating these two claims, M\&H may be able to salvage an important aspect of their view, even if dualism doesn't act as a protective factor.
} 
the individual. The challenging of deeply held beliefs can lead to dissonance, psychological discomfort, and, in some cases, anxiety, hostility, and depression (Russell \& Jones, 1980). The more deeply held the belief, the more likely it is that negative attitudes will develop toward the self (Elliot \& Devine, 1994), leading to more acute psycho-social maladaptations.

If this "dissonance hypothesis" is correct, it also undercuts the intended appeal of M\&H's preferred conceptual framework: embodied embedded cognition. As they point out, prominent versions of the embodied approach are not dualist. They are instead materialist, although not braincentric, since they emphasize physical entities beyond the brain, such as the body and its interaction with the environment. So even embodied embedded cognition could yield maladaptations, as it likewise conflicts with the intuitive dualism that apparently is tacitly accepted by most people.

In any event, we join M\&H's call for more empirical work on this important topic. We believe their hypothesis that dualism acts as a protective factor, along with other competing hypothesis including our suggested "dissonance hypothesis," is deserving of further empirical attention. Such empirical studies may not only tell us more about maladaptative psycho-social responses to DBS, but also have the power to tell us much more about the mind more generally (e.g., the effect of certain mind-body frameworks on identity and well-being).

Acknowledgement: We would like to thank Eddy Nahmias for helpful comments on an early version of the manuscript.

\section{Bibliography}

Bering, J.M. (2006). The folk psychology of souls. The Behavioral and Brain Sciences, 29, 45362; discussion 462-498.

Bloom, P. (2004). Descartes' baby: How the science of hold development explains what makes us human. New York, NW: Basic Books.

Descartes, R. (1641/1996). Meditation VI in Meditations on the First Philosophy, J. Cottingham (trans.). Cambridge: Cambridge University Press.

Elliot, A.J. \& Devine, P.G. (1994). On the motivational nature of cognitive dissonance:

Dissonance as psychological discomfort. Journal of Personality and Social Psychology, 67 382-394.

Mecacci, G. \& Haselager, W.F.G. (this issue). Stimulating the self: The influence of conceptual frameworks on reactions to Deep Brain Stimulation. American Journal of Bioethics Neuroscience, $x x, \mathrm{xx}-\mathrm{xx}$.

Nadelhoffer, T., Shepard, J., Nahmias, E., Sripada, C., \& Ross, L. (2014). The free will inventory: Measuring beliefs about agency and responsibility. Consciousness and Cognition, 25, 27-41.

Nahmias, E., Shepard, J., \& Reuter, S. (under review). It's OK if 'my brain made me do it': People's intuitions about free will and neuroscientific prediction.

Russell, D. \& Jones, W. H. (1980). When superstition fails: Reactions to disconfirmation of paranormal beliefs. Personality and Social Psychology Bulletin, 6, 83-88. 